\title{
Photoisomerization of the green fluorescence protein chromophore and the meta- and para-amino analogues $\dagger$
}

\author{
Jye-Shane Yang,* Guan-Jhih Huang, Yi-Hung Liu and Shie-Ming Peng \\ Received (in Cambridge, UK) 15th November 2007, Accepted 21st December 2007 \\ First published as an Advance Article on the web 18th January 2008 \\ DOI: $10.1039 / b 717714 c$
}

The $Z \rightarrow E$ photoisomerization and fluorescence quantum yields for the wild-type green fluorescence protein (GFP) chromophore ( $p$-HBDI) and its meta- and para-amino analogues ( $m$-ABDI and $p$-ABDI) in aprotic solvents (hexane, THF, and acetonitrile) and protic solvents (methanol and $10-20 \% \mathrm{H}_{2} \mathrm{O}$ in THF) are reported. The dramatic decrease in the quantum yields on going from aprotic to protic solvents indicates the important role of solvent-solute hydrogen bonding in the nonradiative decay pathways. The enhanced fluorescence of $m$-ABDI is also discussed.

The green fluorescence protein (GFP) discovered in the Pacific jellyfish Aequorea victoria has been widely used as a biological marker. ${ }^{1}$ The green fluorescence $(508 \mathrm{~nm})$ is known to result from the anionic form of the chromophore, $p$-hydroxybenzylideneimidazolinone $(p-\mathrm{HBI})$, through excited-state proton transfer (ESPT) from the phenolic oxygen to the protein matrix. ${ }^{1}$ However, the dramatic difference between the fluorescence quantum yield $\left(\Phi_{\mathrm{f}}\right)$ for $p$-HBI in the protein $\beta$-barrel $\left(\Phi_{\mathrm{f}} \sim 0.8\right)$ and that in fluid solutions $\left(\Phi_{\mathrm{f}}<10^{-3}\right)$ has puzzled scientists for many years. ${ }^{1-10}$ More specifically, a unified answer for the questions as to: (1) what the ultrafast nonradiative decay pathway is for both the neutral and anionic forms of the free chromophore, and (2) how the protein matrix suppresses such a decay route so efficiently, remained to be established. In this context, the photodynamics of the dimethyl derivative of the GFP chromophore $(p \text {-HBDI })^{2-6}$ and many other related model systems ${ }^{7,8}$ and GFP mutants ${ }^{7,9}$ has been extensively investigated.

The currently discussed nonradiative decay mechanisms for $p$-HBDI in fluid solutions are all associated with its torsional motions, including (a) the torsion of the exocyclic $\mathrm{C}-\mathrm{C}$ bond $(\varphi)$ (see Chart 1) that leads to the formation of a twisted intramolecular charge transfer (TICT) state, and either (b) the $\mathrm{C}=\mathrm{C}$ bond torsion $(\tau)$ or $(\mathrm{c})$ a concerted torsion of both the $\mathrm{C}-\mathrm{C}$ and $\mathrm{C}=\mathrm{C}$ bonds (i.e., the hula twist) that leads to $Z \rightarrow E$ photoisomerization. However, none of these mechanisms can satisfactorily account for all the key experimental and computational results. For example, the $\mathrm{C}=\mathrm{C}$ bond torsion ${ }^{3,4}$ conflicts with the volume-conserving nature of the decay process and with the fast ground-state recovery of $p$-HBDI in alcohols (i.e., little $E$-isomer formation). ${ }^{2}$ In the case of the $\mathrm{C}-\mathrm{C}$ bond

Department of Chemistry, National Taiwan University, Taipei, Taiwan 10617.E-mail: jsyang@ntu.edu.tw

$\dagger$ Electronic Supplementary Information (ESI) available: Experimental methods, synthetic details, and spectroscopic data for $p$-ABDI and $m$-ABDI; crystal structure data for $m$-ABDI (CCDC number 667977). torsion, ${ }^{5}$ not only its disagreement with a volume-conserving path but also the absence of any explicit conical intersection near the twisted intermediate is the deficiency. ${ }^{3}$ Although a concerted torsion of the $\mathrm{C}-\mathrm{C}$ and $\mathrm{C}=\mathrm{C}$ bond $^{2,6}$ is volumeconserving, it encounters an unfavorable uphill coordinate. ${ }^{3,4}$ Another common problem for the TICT and hula-twist mechanisms is the lower possibility of these torsions being effectively inhibited by the protein matrix. ${ }^{10}$

We report herein a new approach toward understanding the nonradiative pathways of $p$-HBDI through quantitative determination of the $Z \rightarrow E$ photoisomerization quantum yields $\left(\Phi_{\mathrm{ZE}}\right)$ for $p$-HBDI and its para- and meta-amino analogues $p$-ABDI and $m$-ABDI in different solvents. Our results have led to a new excited-decay mechanism proposed for $p$-HBDI in fluid solutions.

Our design concepts for the investigation of ABDIs are manifold. First, the excited-state behaviour of the anionic form of $p$-HBDI (a phenolate) might be correlated to that of $p$-ABDI (an aniline), because the degree of photoinduced intramolecular charge transfer (ICT) might be similar, as reflected by the same $\mathrm{p} K_{\mathrm{a}}$ changes $\left(\mathrm{p} K_{\mathrm{a}}=6\right)$ on going from $\mathrm{S}_{0}$ to $\mathrm{S}_{1}$ for 2-naphthol (with a phenolate-like conjugate base) and the conjugated acid of 2-aminonaphthalene. ${ }^{11}$ This correlation might resolve the solubility problem upon measuring $\Phi_{\mathrm{f}}$ and $\Phi_{\mathrm{ZE}}$ for the anionic form of $p$-HBDI in nonpolar solvents. Second, a reliable measurement of $\Phi_{\mathrm{ZE}}$ requires a stable $E$ isomer of $p$-HBDI either in the neutral or anionic forms. However, it has been reported that $p$-HBDI undergoes efficient thermal $E \rightarrow Z$ isomerization in $\mathrm{D}_{2} \mathrm{O}$ and $\mathrm{CD}_{3} \mathrm{OD}$ at room temperature. ${ }^{12,13}$ Whereas Falk and coworkers have attributed the facile thermal isomerization to a weak double-bond character of the exocyclic $\mathrm{C}=\mathrm{C}$ bond due to significant delocalization of the oxygen lone-pair electrons, ${ }^{13}$ an alternative interpretation is the presence of an acidic phenol group (the $\mathrm{p} K_{\mathrm{a}}$ value for phenol is 10.0 in $\mathrm{H}_{2} \mathrm{O}$ and 18.0 in DMSO), ${ }^{14}$ which self-catalyzes the isomerization reaction. Along this line, the thermal isomerization would become even more efficient upon irradiation because of the enhanced acidity of $p$-HBDI in $\mathrm{S}_{1} \cdot{ }^{8 c}$ Since the ABDIs are free of acidic groups (the
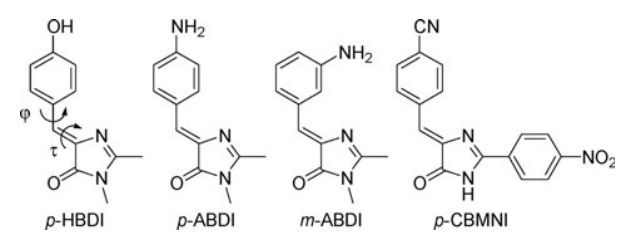

Chart 1 

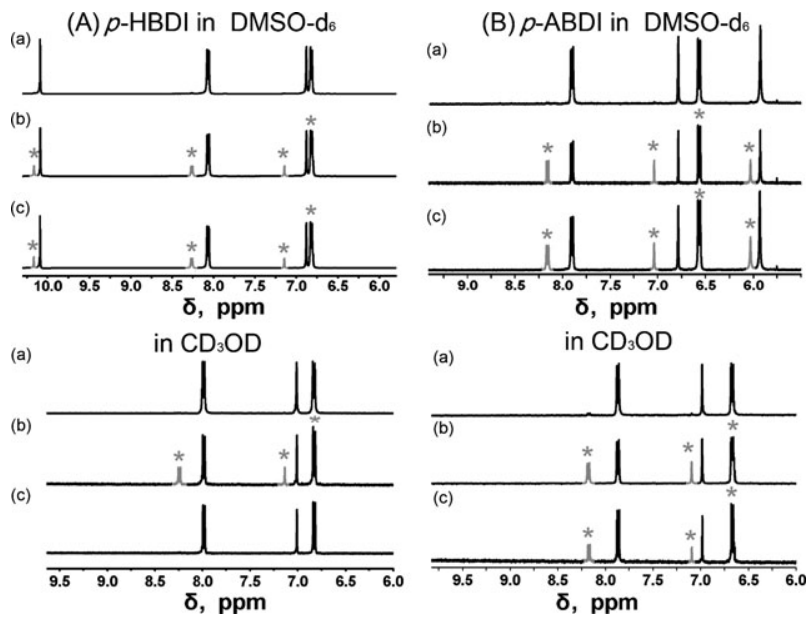

Fig. 1 The ${ }^{1} \mathrm{H}$ NMR spectra for (A) $p$-HBDI and (B) $p$-ABDI $(\sim 2$ $\mathrm{mM}$ ) in DMSO- $d_{6}$ and $\mathrm{CD}_{3} \mathrm{OD}$ (a) before and (b) after $20 \mathrm{~min}$ of irradiation with $350 \mathrm{~nm}$ light and (c) after $24 \mathrm{~h}$ at room temperature in the dark. The $E / Z$ ratio is the same for the conditions (b) and (c) for all cases except for $p$-HBDI in $\mathrm{CD}_{3} \mathrm{OD}$, where the $Z$ form completely isomerized back to the $E$ form.

$\mathrm{p} K_{\mathrm{a}}$ value for aniline is 30.7 in DMSO), ${ }^{15}$ complication of the thermal $E \rightarrow Z$ isomerization for the determined $\Phi_{\mathrm{ZE}}$ would be reduced. Indeed, as shown in Fig. 1, the $E \rightarrow Z$ thermal isomerization of $p$-HBDI is negligible in DMSO- $d_{6}$ but efficient in $\mathrm{CD}_{3} \mathrm{OD}$, consistent with the larger $\mathrm{p} K_{\mathrm{a}}$ value of phenol in aprotic $v s$. protic solvents. In addition, the $E$ isomers of $p$-ABDI and $m$-ABDI are rather stable in both DMSO- $d_{6}$ and $\mathrm{CD}_{3} \mathrm{OD}$. Third, comparison of the amino-modified GFP chromophores and aminostilbenes is inherently interesting, because the issue of TICT formation vs. photoisomerization has also been extensively discussed for the latter systems. ${ }^{16}$ Our recent studies on trans-aminostilbenes have shown that the single-bond torsion that leads to the TICT state does not couple with the trans $\rightarrow$ cis double-bond torsion. ${ }^{16}$ In other words, the formation of a TICT state competes with the trans $\rightarrow$ cis photoisomerization, leading to low photoisomerization quantum yields ( $\Phi_{\mathrm{ts}}$ ). Thus, the $\Phi_{\mathrm{ZE}}$ values might allow us to elucidate the excited-decay mechanism for ABDIs and thus for $p$-HBDI, provided that the $\mathrm{C}-\mathrm{C}$ and $\mathrm{C}=\mathrm{C}$ bond torsions in the latter are also decoupled.

The ABDIs were synthesized using our modification of Niwa's procedure described in the ESI $\dagger \cdot{ }^{17}$ As is the case for $p$-HBDI, the $Z$ isomers of the ABDIs were obtained. One piece of solid evidence is provided by the X-ray crystal structure of $m$-ABDI $\dagger$.

Both the values of $\Phi_{\mathrm{f}}$ and $\Phi_{\mathrm{ZE}}$ for $p$-HBDI, $p$-ABDI, and $m$-ABDI in protic $\left(\mathrm{MeOH}\right.$ and $\left.\mathrm{H}_{2} \mathrm{O}-\mathrm{THF}\right)$ and aprotic (hexane, THF, and $\mathrm{MeCN}$ ) solvents are shown in Table 1. Since the calculated potential energy profiles for $p$-HBDI ${ }^{6 a}$ resemble those for stilbenes, where the conical intersection locates at a twisted angle of $90^{\circ}$, it is reasonable to assume that the probability of product formation for the Evs.Z isomer from such a perpendicularly twisted geometry is $c a .50 \%$, in analogy to the case of stilbenes. ${ }^{18}$ As a result, the quantum yield for the $\mathrm{C}=\mathrm{C}$ bond torsion $\left(\Phi_{\mathrm{d}}\right)$ can be obtained as $2 \Phi_{\mathrm{ZE}}$. In all the investigated aprotic solvents, the sum of $\Phi_{\mathrm{f}}+\Phi_{\mathrm{d}}\left(=\Phi_{\mathrm{f}}+2 \Phi_{\mathrm{ZE}}\right)$ is close to $1.0(0.90-1.08)$ within experimental error for both $p$-ABDI and $m$-ABDI. We can thus conclude that in aprotic solvents the nonradiative decay channel is mainly the $\mathrm{C}=\mathrm{C}$ bond torsion. The absence of solvent-polarity dependence of the $\Phi_{\mathrm{f}}+2 \Phi_{\mathrm{ZE}}$ values and the observation of an increase of $\Phi_{\mathrm{f}}$ at the expense of $\Phi_{\mathrm{ZE}}$ on going from $p$-ABDI to $m$-ABDI support the assumption that $\Phi_{\mathrm{d}}=2 \Phi_{\mathrm{ZE}}$ and the conclusion. It should also be noted that the much larger $\Phi_{\mathrm{f}}$ values for $m$-ABDI $v s . p$-ABDI in aprotic solvents resembles the case of the $m$ - vs. $p$-aminostilbene. ${ }^{19}$ Evidently, there exists a close photochemical correlation between the GFP chromophore and aminostilbenes. To our knowledge, the fluorescence quantum yield for $m$-ABDI in hexane is the largest among the various derivatives of the GFP chromophore. ${ }^{7,20}$

In contrast, the $\mathrm{C}=\mathrm{C}$ bond torsion no longer dominates the nonradiative decay of ABDIs in protic solvents on the basis of the fact that the value of $\Phi_{\mathrm{f}}+2 \Phi_{\mathrm{ZE}}$ is much lower than 1.0 (Table 1) and solvent-dependent. Although the $\Phi_{\mathrm{ZE}}$ values in pure water were unavailable due to the solubility problem, low values of $\Phi_{\mathrm{ZE}}$ for both ABDIs in pure water can be readily predicted on the basis of the dramatic reduction of $\Phi_{\mathrm{ZE}}$ on going from pure THF to that containing only $10-20 \%$ water. The lower $\Phi_{\mathrm{ZE}}$ values for $m$-ABDI vs.p-ABDI is consistent with the slower photoisomerization process and thus the lower ability to compete with the new nonradiative decay channel. Regarding the new nonradiative decay channel, the possibility of TICT state formation through the $\mathrm{C}-\mathrm{C}$ bond torsion can be excluded, because the marked difference in acetonitrile $v s$. methanol could hardly be interpreted in terms of the comparable solvent polarity. ${ }^{16}$ Furthermore, the related chromophore $p$-CBMNI (see Chart 1) also displays a dramatic decrease in $\Phi_{\mathrm{f}}$ on going from aprotic dioxane $(0.22)$ to protic glycerol $(0.023),{ }^{7}$ but it cannot be a consequence of TICT formation due to the lack of an explicit electron donor. Therefore, hydrogen bonding-induced deactivation of the excited ABDIs is proposed, since the phenomenon of $\mathrm{H}$ bond-mediated vibronic coupling to the ground state is known to be an important radiationless decay channel for both interand intramolecular H-bonded species. ${ }^{21,22}$ In particular, it has been well demonstrated by studies of several arylethylenes that the ultrafast $Z \rightarrow E$ photoisomerization can be completely inhibited by intramolecular H-bonding. ${ }^{21}$

Table 1 Quantum yields for fluorescence $\left(\Phi_{\mathrm{f}}\right)$ and $Z \rightarrow E$ photoisomerization $\left(\Phi_{\mathrm{ZE}}\right)$ for $p$-HBDI, $p$-ABDI, and $m$-ABDI in protic and aprotic solvents

\begin{tabular}{|c|c|c|c|c|c|c|}
\hline \multirow[b]{2}{*}{ Solvent } & \multicolumn{2}{|c|}{$p$-HBDI } & \multicolumn{2}{|c|}{$p$-ABDI } & \multicolumn{2}{|c|}{$m$-ABDI } \\
\hline & $\Phi_{\mathrm{f}}$ & $\Phi_{\mathrm{ZE}}$ & $\Phi_{\mathrm{f}}$ & $\Phi_{\mathrm{ZE}}$ & $\Phi_{\mathrm{f}}$ & $\Phi_{\mathrm{ZE}}$ \\
\hline Hex & $<10^{-3}$ & $0.53^{a}$ & $<10^{-3}$ & $0.45^{a}$ & 0.34 & $0.37^{a}$ \\
\hline THF & $<10^{-3}$ & 0.46 & $<10^{-3}$ & 0.49 & 0.28 & 0.35 \\
\hline $\mathrm{MeCN}$ & $<10^{-3}$ & $0.48^{a}$ & $<10^{-3}$ & $0.50^{a}$ & 0.16 & $0.45^{a}$ \\
\hline $\mathrm{MeOH}$ & $<10^{-3}$ & $\sim 0.1$ & $<10^{-3}$ & 0.17 & $<10^{-3}$ & 0.08 \\
\hline $\mathrm{H}_{2} \mathrm{O}-\mathrm{THF}^{b}$ & $<10^{-3}$ & $\sim 0.2$ & $<10^{-3}$ & 0.37 & $<10^{-3}$ & 0.08 \\
\hline $\mathrm{H}_{2} \mathrm{O}-\mathrm{THF}^{c}$ & $<10^{-3}$ & $\sim 0.1$ & $<10^{-3}$ & 0.28 & $<10^{-3}$ & 0.06 \\
\hline
\end{tabular}

${ }^{a}$ For the purpose of solubility, Hex and MeCN contain $20 \%$ THF for the measurement of $\Phi_{\mathrm{ZE}}{ }^{b} \mathrm{H}_{2} \mathrm{O}-\mathrm{THF}=1: 9(\mathrm{v} / \mathrm{v}) \cdot{ }^{c} \mathrm{H}_{2} \mathrm{O}-\mathrm{THF}=$ $2: 8(\mathrm{v} / \mathrm{v})$. 


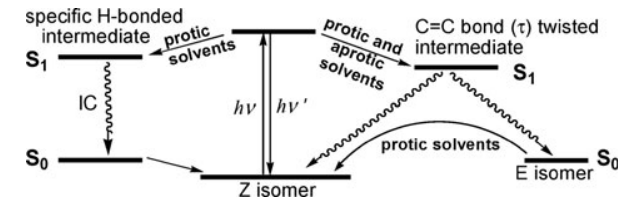

Fig. 2 Simplified scheme for the radiationless decay channels for $p$ HBDI and its amino analogues $p$-ABDI and $m$-ABDI in bulk protic vs. aprotic solvents.

The photochemical behaviour of $p$-HBDI essentially parallels that of $p$-ABDI (Table 1), although attempts to obtain more accurate $\Phi_{\mathrm{ZE}}$ values for $p$-HBDI in protic solvents are hampered by the unstable $E$ isomer in protic solvents. ${ }^{12,13}$ The similar behaviour of $p$-HBDI and $p$-ABDI is reminiscent of the common photodynamic scheme for the neutral and anionic forms of $p$-HBDI. ${ }^{1,2}$ Thus, the correlation between $p$-ABDI and the anionic $p$-HBDI appears to be appropriate.

Accordingly, we might conclude that $p$-HBDI simultaneously possesses two different ultrafast raditionless decay channels (Fig. 2). Whereas the decay in protic solvents involves both the solute-solvent $\mathrm{H}$-bond-mediated internal conversion (major) and $\mathrm{C}=\mathrm{C}$ bond torsion (minor), the $\mathrm{C}=\mathrm{C}$ bond torsion alone accounts for the decay in aprotic solvents. It is important to note that $\mathrm{H}$-bonding-induced deactivation is consistent with the volume-conserving photodynamic scheme observed for $p$-HBDI in alcohols. ${ }^{2}$ In addition, the deactivating $\mathrm{H}$-bonded intermediate appears to be different from the Franck-Condon excited state, and its formation requires the reorganization of the solvent $\mathrm{H}$-bonding network and vibrational relaxations of the excited $p$-HBDI in order to account for the previously proposed two-state two-mode model. ${ }^{2 c}$ Although the exact deactivating $\mathrm{H}$-bonding modes remain to be determined, the most possible candidates are the $\mathrm{H}$-bonds between the solvent molecules (H-bond donor) and the imidazolinone group (H-bond acceptor) of $p$-HBDI. One reason is that the imidazolinone group becomes a better $\mathrm{H}$-bond acceptor in the lowest excited state $\left(\mathrm{S}_{1}\right)$ than in the ground state $\left(\mathrm{S}_{0}\right)$ as a result of ICT. Another reason is that the imino nitrogen of the imidazolinone group is not $\mathrm{H}$-bonded to any water molecules or neighbouring residues inside the protein $\beta$ barrel. ${ }^{1}$ It appears that the protein matrix not only suppresses the $\mathrm{C}=\mathrm{C}$ bond torsion ${ }^{3,10}$ but also prevents the formation of the specific $\mathrm{H}$-bonding modes in the excited state, which accounts for the high fluorescence quantum yield of GFP. It should be pointed out that a general $\mathrm{H}$-bonding effect in the excited-state decay of $p$-HBDI and its derivatives has been noted. ${ }^{2,7}$ However, the argument of the presence of certain H-bonding modes that dominate the nonradiative decays of $p$-HBDI in protic solvents had not been recognized. Meech et al. had considered solvent-chromophore H-bonding as a possible nonradiative mechanism for $p$-HBDI, but it was finally ruled out in view of the fact that this channel alone cannot interpret their data in acetonitrile (aprotic) $v s$. methanol (protic). ${ }^{2 c}$

In summary, we have provided for the first time the $Z \rightarrow E$ photoisomerization quantum yields for $p$-HBDI and its amino analogues $p$-ABDI and $m$-ABDI in both aprotic and protic solvents. In addition, $m$-ABDI displays record-high fluorescence in aprotic solvents at room temperature. The solventdependent fluorescence and photoisomerization behaviour has led to a new photodynamic picture for the GFP chromophore. Further studies toward the identification of the deactivating $\mathrm{H}$-bonding modes for $p$-HBDI in protic solvents are in progress in our laboratory.

We thank the National Science Council and Ministry of Education of Taiwan, ROC, for financial support.

\section{Notes and references}

1 (a) R. Y. Tsien, Annu. Rev. Biochem., 1998, 67, 509; (b) M. Zimmer, Chem. Rev., 2002, 102, 759; (c) M. Zimmer, Cis-trans Isomerization in Biochemistry, ed. C. Dugave, Wiley-VCH, Weinheim, 2006, pp. 77.

2 (a) N. M. Webber, K. L. Litvinenko and S. R. Meech, J. Phys. Chem. $B, 2001,105,8036$; (b) K. L. Litvinenko, N. M. Webber and S. R. Meech, J. Phys. Chem. A, 2003, 107, 2616; (c) D. Mandal, T. Tahara and S. R. Meech, J. Phys. Chem. B, 2004, 108, 1102; (d) N. M. Webber and S. R. Meech, Photochem. Photobiol. Sci., 2007, 6, 976.

3 P. Altoe, F. Bernardi, M. Garavelli, G. Orlandi and F. Negri, $J$. Am. Chem. Soc., 2005, 127, 3952.

4 A. Usman, O. F. Mohammed, E. T. J. Nibbering, J. Dong, K. M. Solntsev and L. M. Tolbert, J. Am. Chem. Soc., 2005, 127, 11214.

5 (a) M. E. Martin, F. Negri and M. Olivucci, J. Am. Chem. Soc., 2004, 126, 5452; (b) S. S. Stavrov, K. M. Solntsev, L. M. Tolbert and D. Huppert, J. Am. Chem. Soc., 2006, 128, 1540.

6 (a) W. Weber, V. Helms, J. A. McCammon and P. W. Langhoff, Proc. Natl. Acad. Sci. U. S. A., 1999, 96, 6177; (b) A. Toniolo, S. Olsen, L. Manohar and T. J. Martínez, Faraday Discuss., 2004, 127, 149.

7 A. Follenius-Wund, M. Bourotte, M. Schmitt, F. Iyice, H. Lami, J.J. Bourguignon, J. Haiech and C. Pigault, Biophys. J., 2003, 85, 1839.

8 (a) A. D. Kummer, C. Kompa, H. Niwa, T. Hirano, S. Kojima and M. E. Michel-Beyerle, J. Phys. Chem. B, 2002, 106, 7554; (b) K.-Y. Chen, Y.-M. Cheng, C.-H. Lai, C.-C. Hsu, M.-L. Ho, G.-H. Lee and P.-T. Chou, J. Am. Chem. Soc., 2007, 129, 4534; (c) J. Dong, K. M. Solntsev, O. Poizat and L. M. Tolbert, J. Am. Chem. Soc., 2007, 129, 10084.

9 (a) A. D. Kummer, J. Wiehler, H. Rehaber, C. Kompa, B. Steipe and M. E. Michel-Beyerle, J. Phys. Chem. B, 2000, 104, 4791; (b) D. C. Loos, S. Habuchi, C. Flors, J. Hotta, J. Wiedenmann, G. U. Nienhaus and J. Hofkens, J. Am. Chem. Soc., 2006, 128, 6270.

10 M. C. Chen, C. R. Lambert, J. D. Urgitis and M. Zimmer, Chem. Phys., 2001, 270, 157.

11 E. V. Anslyn and D. A. Dougherty, Modern Physical Organic Chemistry, University Science Books, Sausalito, CA, 2006, pp. 965.

12 X. He, A. F. Bell and P. J. Tonge, FEBS Lett., 2003, 549, 358.

13 (a) B. Hager, B. Schwarzinger and H. Falk, Monatsh. Chem., 2006, 137, 163; (b) The tryptophan-derived GFP chromophore was also found to undergo thermal $E \rightarrow Z$ isomerization with a slower rate than that for $p$-HBDI (K. Fendler, B. Hager and H. Falk, Monatsh. Chem., 2007, 138, 859), which can also be attributed to the slightly acidic indole group ( $K_{\mathrm{a}}=20.95$ in DMSO) (ref. 16).

14 F. G. Bordwell, R. J. McCallum and W. N. Olmstead, J. Org. Chem., 1984, 49, 1424.

15 F. G. Bordwell, G. E. Drucker and H. E. Fried, J. Org. Chem., 1981, 46, 632.

16 (a) J.-S. Yang, K.-L. Liau, C.-M. Wang and C.-Y. Hwang, J. Am. Chem. Soc., 2004, 126, 12325; (b) J.-S. Yang, K.-L. Liau, C.-W. Tu and C.-Y. Hwang, J. Phys. Chem. A, 2006, 110, 8003-8010; (c) J.-S. Yang, K.-L. Liau, C.-Y. Li and M.-Y. Chen, J. Am. Chem. Soc., 2007, 129, 13183.

17 S. Kojima, H. Ohkawa, T. Hirano, S. Maki, H. Niwa, M. Ohashi, S. Inouye and F. I. Tsuji, Tetrahedron Lett., 1998, 39, 5239.

18 (a) J. Saltiel and J. L. Charlton, in Rearrangements in Ground and Excited States, ed. P. de Mayo, Academic Press, New York, 1980, vol. 3, pp. 25; (b) H. Görner and H. J. Kuhn, Adv. Photochem., 1995, 19, 1.

19 F. D. Lewis, R. S. Kalgutkar and J.-S. Yang, J. Am. Chem. Soc., 1999, 121, 12045.

20 Y. You, Y. He, P. E. Burrows, S. R. Forrest, N. A. Petasis and M. E. Thompson, Adv. Mater., 2000, 12, 1678.

21 F. D. Lewis and J. -S. Yang, J. Phys. Chem., 1996, 100, 14560, and references cited therein.

22 L. Biczók, T. Bérces and H. Linschitz, J. Am. Chem. Soc., 1997, 119, 11071, and references cited therein. 